\title{
Letters
}

Website: bmj.com

Email: letters@bmj.com

\section{Wanted: social contract for practice of medicine}

\section{Ethical framework for using medical} records is needed

EDITOR-I support the idea of a social contract for the practice of medicine, as outlined by Gillon et al in their editorial. ${ }^{1}$ I write particularly from the perspective of surveillance of diseases.

Effective surveillance leaves no option for patients to opt out. That does not mean that patients have to be identified. Equally, no one can be forced to undergo a specific investigation procedure, but in the interests of public health we do need to identify the cause of epidemic diseases and patients are investigated quite specifically for protecting the health of the community rather than for individual patient management. By the system of legally required official notification there is a recognised mechanism for the notification of disease for which contact tracing is generally considered desirable. There are, however, many illnesses for which it is important to know the burden of disease.

In the context of the social contract to which the editorial by Gillon et al refers, I hope that this could be extended to include the establishment of an ethical arrangement specifically dedicated to issues of surveil-

\section{Advice to authors}

We prefer to receive all responses electronically, sent directly to our website. Processing your letter will be delayed unless it arrives in an electronic form.

We are now posting all direct submissions to our website within 24 hours of receipt and our intention is to post all other electronic submissions there as well. All responses will be eligible for publication in the paper journal.

Responses should be under 400 words and relate to articles published in the preceding month. They should include $\leqslant 5$ references, in the Vancouver style, including one to the BMJ article to which they relate. We welcome illustrations.

Please supply each author's current appointment and full address, and a phone or fax number or email address for the corresponding author. We ask authors to declare any competing interest. Please send a stamped addressed envelope if you would like to know whether your letter has been accepted or rejected.

Letters will be edited and may be shortened.

bmj.com

letters@bmj.com lance. The ethics of relationships between individual doctors and patients are established and controlled by the General Medical Council. The ethics of clinical research have their own regulatory framework dominated by the principle of written informed consent.

Surveillance cannot function on the basis of individual informed consent. Much surveillance can be undertaken avoiding patient identification for statistical purposes. Surveillance is not experimental research, and the most importance source of surveillance data is the medical record. Intelligent management of a health service and protection of a nation's health calls for sensible use of medical records. An appropriate ethical framework for doing so is needed.

\section{M Fleming director}

Roval College of General Practitioners, London SW7 1PU

1 Gillon R, Higgs R, Boyd K, Callaghan B, Hoffenberg R.
Wanted: a social contract for the practice of medicine. BMJ 2001;323:64. (14 July.)

\section{Another expert body would be mistrusted}

EDITOR-With reference to the article by Gillon et al, the need for ethical guidelines in disputes between doctors and patients is urgent, but the notion that a high level committee can furnish us with these is doomed.

All citizens should be concerned with this debate, and the best judge of these difficulties is a person in a jury of 12 , informed by experts and counsel as in any court of law. Whether a schizophrenic patient's rights of confidentiality should overwhelm the safety of society, for example, is a matter that is already being dealt with in the courts. Our current breakdown in confidence and trust between layperson and professional is a symptom of unease about committees and bureaucracy to deal promptly and fairly with professional interests, and another body of experts would be equally mistrusted.

N Sarkies consultant ophthalmologist Addenbrookes Hospital, Cambridge CB2 2QQ N.Sarkies@btinternet.com

1 Gillon R, Higgs R, Boyd K, Callaghan B, Hoffenberg R. Wanted: a social contract for the practice of medicine. $B M$ 2001;323:64. (14 July.)

\section{Acceptable practice needs to be} determined by the public

EDitor-The proposal by Gillon et al has its merits. ${ }^{1}$ A standing commission would fill a need in so far as it succeeded in breaking the profession's long held stranglehold on what constitutes socially acceptable medical practice. But I doubt that its establishment by healthcare professionals and patient organisations would achieve this goal.

Professionals invariably dominate such bodies, making consensus a chimera. The suggestions by Gillon et al indicate how little the lessons of Bristol and Alder Hey have impinged on professional ethicists' consciousness. Having suggested that obtaining consent for medical interventions "could" be a definitive norm (it already is on paper and in law), they then propose presumptive norms that destroy the core principle of informed consent-for example, experimentation on patients requiring emergency care without their agreement. This is going backwards, rather than learning from patients and the public's reactions to recent disclosures of medical practices that were apparently acceptable to the profession.

Only if such a body consisted of general members of the public, with healthcare professionals and patient representatives involved merely as expert witnesses, might a standing commission produce genuinely independent recommendations.

Roger M Goss director

Patient Concern, PO Box 23732, London SW5 9FY rogerconcern@hotmail.com

1 Gillon R, Higgs R, Boyd K, Callaghan B, Hoffenberg R Wanted: a social contract for the practice of medicine. $B M$ 2001;323:64. (14 July.)

\section{Delivery by caesarean section}

Increased numbers of caesareans do not match diagnoses of fetal distress

EDitor-MacKenzie and Cooke say that the main documented indication for intrapartum caesarean section is fetal distress. ${ }^{1}$ Tuffnell et al looked at how the interval between the decision to perform an emergency caesarean section and the time of delivery affected fetal outcome. ${ }^{2}$ They concluded that a delayed decision to delivery time was an unusual cause of neonatal problems.

To help put these papers into context, we looked at the West Sussex births database of 152284 births between 1980 and 1999 . Over this period, the diagnosis of fetal distress has doubled from $6.4 \%$ to $13 \%$ of all births, and the percentage of caesarean sections has increased from $9.7 \%$ to $20.2 \%$ of all births. The proportion of caesarean sections where a diagnosis of fetal distress is recorded has increased from $15.4 \%$ to $19.3 \%$ of all caesarean sections. This implies that increasing numbers of caesarean 
Prepartum diagnosis of fetal distress compared with Apgar score at 1 minute: West Sussex births data, 1980-99. Values are numbers of deliveries unless stated otherwise

\begin{tabular}{lcr} 
& $\begin{array}{c}\text { Apgar } \\
\text { score }<\mathbf{5}\end{array}$ & $\begin{array}{c}\text { Apgar } \\
\text { score }>\mathbf{5}\end{array}$ \\
\hline No of deliveries: & & \\
\hline Fetal distress diagnosed & 2553 & 11469 \\
\hline Fetal distress not diagnosed & 7284 & 130978 \\
\hline Sensitivity & $26.0 \%$ & \\
\hline Specificity & $91.9 \%$ & \\
\hline Positive predictive value & $18.2 \%$ & \\
\hline Negative predictive value & $94.8 \%$ & \\
\hline
\end{tabular}

sections are being performed for fetal distress. The doubling in the rate of diagnosis of fetal distress is unlikely to reflect a true increase in the incidence of this condition. There is no evidence that changes in maternal health or clinical care could explain such a dramatic rise. This implies that the diagnosis of fetal distress is imprecise.

We then investigated if the diagnosis of fetal distress was a valid test in predicting poor fetal outcome, which was defined as a one minute Apgar score of less than 5. From 1980 to 1999 , only $18 \%$ of cases diagnosed with fetal distress subsequently had a poor fetal outcome (table). Over the same period, $74 \%$ of babies born with an Apgar score of less than 5 did not have a prepartum diagnosis of fetal distress. Therefore, the diagnosis of fetal distress is not a sensitive test for predicting poor fetal outcome (sensitivity 26\%, specificity 92\%). This is true even if we examine the most recent data for 1996-8 (sensitivity $30 \%$, specificity $88 \%$ ). The resulting excess of false positive results tends to encourage unnecessary caesarean sections.

Therefore, our analysis implies three things. Firstly, increasing numbers of caesarean sections are being performed for fetal distress. Secondly, the diagnosis of fetal distress is imprecise and a poor predictor of fetal outcome. Finally, the result is a tendency for unnecessary caesarean sections. Until firm and consistent diagnostic criteria for fetal distress are agreed, it is difficult to interpret studies looking at the decision to delivery time for emergency caesarean sections.

Ashis Banerjee senior house officer public health James Hollinshead senior house officer public health james.hollinshead@wsha.nhs.uk

Edward Williams consultant public health

Public Health Department, West Sussex Health

Authority, Worthing, West Sussex BN12 6BT

1 MacKenzie IZ, Cooke I. Prospective 12 month study of 30 minute decision to delivery intervals for "emergency" caeminute decision to delivery intervals for "emergency" cae-
sarean section. Observational case series. BMJ sarean section. Obser
2001;322:1334-5. (2 June.)

2 Tuffnell DJ, Wilkinson K, Beresford N. Interval between Tuffnell DJ, Wilkinson K, Beresford N. Interval between
decision and delivery by caesarean section-are current standards achievable? BMJ 2001;322:1330-3. (2 June.)

Effective system of mobilisation is used in Singapore

EDITOR-We agree with Tuffnell et al that an emergency caesarean section is a complex multidisciplinary procedure requiring the timely assembly of staff.' One factor that was not addressed in their paper was the team's response time. During our specialist registrar rotations in the United Kingdom, we observed that many units rely on paging each individual on the team. In an emergency, this process can be cumbersome, requiring a valuable member of the delivery suite team making multiple phone calls. Furthermore, the recipient may be unaware of the urgency of the page.

The KK Women's and Children's Hospital in Singapore is the largest maternity hospital in the country, delivering about 15000 babies a year. It uses a public announcement system to mobilise the team when an emergency caesarean section is required. Each team member is required to be aware of their own specific roles in such an emergency and respond appropriately.

Once a decision for an emergency caesarean section is made, a "code green" is activated via the telephone operator through a public announcement system. All team members receive the urgent message simultaneously. This ensures the rapid assembly of all the necessary staff at the appropriate locations including the mobilisation of support midwives and personnel involved in the transfer of the patient to the operating theatre. In addition the theatre staff can begin the process of receiving the patient and preparing for surgery.

Yeap et al examined 113 consecutive emergency caesarean sections over one year, accounting for $0.7 \%$ of the total 16267 deliveries (sixteenth FIGO world congress of gynaecology and obstetrics, Washington, DC, September 2000). The rate of caesarean sections for this period was $20.7 \%$. The mean time interval from decision to delivery was 14.9 minutes. The arbitrary time standard of 30 minutes was achieved in 112 out of 113 cases. In the remaining case, delivery was achieved in 32 minutes. Fetal distress on cardiotocography and fetal bradycardia accounted for $16 \%$ and $39 \%$ of cases, respectively. The code green model is simple and reliable, eliciting a swift and coordinated response, thereby reducing the time interval to delivery. Although such a system may not be directly applicable to units that do not use a public announcement system, the principle may readily be modified to existing paging facilities.

Horng Yen Wee registrar

Department of Maternal Fetal Medicine mrwee@talk21.com

Swee Chong Quek registrar

Division of Obstetrics and Gynaecology,

KK Women's and Children's Hospital, Singapore

1 Tuffnell DJ, Wilkinson K, Beresford N. Interval between decision and delivery by caesarean section-are current standards achievable? Observational case series. BMJ 2001;322:1330-3. (2 June.)

\section{Caesarean section urgency-use clinical definitions}

Editor-The papers by Tuffnell et al and MacKenzie and Cooke, together with the accompanying editorial by James, reinforce the concept that the definition of urgency of caesarean section should not incorporate the intended interval between decision and delivery. ${ }^{1-4}$ If, on the one hand, the actual interval is greater than the intended interval there may be medicolegal consequences; on the other hand, there could be a danger to patients if undue haste is used to achieve a preselected interval that is not clinically warranted. The degree of urgency may even decrease after the decision-for example, after successful use of intrauterine resuscitation.

The Royal Colleges of Obstetrics and Gynaecology and Anaesthetists and the Obstetric Anaesthetists Association support the use of a new four point urgency category for caesarean section that is based on clinical definitions, ${ }^{5}$ which produces more consistent interobserver rating than the intended interval.

The 30 minute standard for the interval between decision and delivery, which originated in the United States as a compromise that would allow senior staff not resident in hospital to attend, is too long to allow delivery of a live infant in cases of complete placental failure-for example, abruption. We disagree with James that this arbitrary figure is a useful audit standard. We do, however, support the use of data on the interval for audit. In a draft version of standard 10.3.1, from the clinical negligence scheme for trusts, it is stated that a standard is set for the interval which should be annually reviewed and remedial measures instituted if it was not met. If data in the urgency category are collected that use the agreed definitions ${ }^{4}$ as well as data on the interval (as was done for last year's national sentinel audit of caesarean section), individual units may produce evidence based local standards for interval according to urgency category. These will account for individual circumstances-for example, the distance of the operating theatre from the labour rooms, staffing levels, etc-and avoid the problem of trying (and failing) to achieve a 30 minute standard for all caesarean sections for fetal distress.

S Michael Kinsella consultant anaesthetist

St Michael's Hospital, Bristol BS2 8EG

Stephen.Kinsella@ubht.swest.nhs.uk

D Nuala Lucas specialist registrar anaesthetist Northwick Park Hospital, Harrow HA1 3JU

Steven M Yentis consultant anaesthetis

Anita Holdcroft reader in anaesthesia

Chelsea and Westminster Hospital, London SW10 9NH

Anne E May consultant anaesthetist Leicester Royal Infirmary, Leicester LE1 5WW

Michael Wee consultant anaesthetist

Poole Hospital, Poole BH15 2JB

P Neville Robinson consultant anaesthetist Northwick Park Hospital, Harrow HA1 3JU

The authors are the same as in reference 4 below and in reference 14 in the paper by Tuffnell et al.

1 Tuffnell DJ, Wilkinson K, Beresford N. Interval between decision and delivery by caesarean section-are curren standards achievable? Observational case series. BMJ 2001;322:1330-3. (2 June.)

2 MacKenzie IZ, Cooke I. Prospective 12 month study of 30 minute decision to delivery intervals for "emergency" caesarean section. BMJ 2001;322:1334-5. (2 June.)

3 James D. Caesarean section for fetal distress. BMJ 2001;322:1316-7. (2 June.)

4 Lucas DN, Yentis SM, Kinsella SM, Holdcroft A, May AE, Wee M, et al. Urgency of caesarean section: a new classification. JR Soc Med 2000:93:346-50.

5 Anonymous. Classification of urgency of caesarean Aection. $R C O G$ Ness $2000 ; 7: 64$ 


\section{Don't throw the baby out with the bath water}

EDITOR-We congratulate Tuffnell et al and MacKenzie and Cooke on their papers concerning the audit standard of 30 minutes from decision to delivery. ${ }^{12}$ We agree that there is no published scientific evidence in favour of a 30 minute limit, although this standard has been widely accepted. But, as pointed out, in many pressing cases more urgent delivery will be necessary to provide a good outcome and in others delivery beyond 30 minutes will have little impact on outcome.

Similar audits in our own unit have produced comparable results. Most recently, we have shown a mean time of 45 minutes with only $20 \%$ achieved in less than 30 minutes. But what we, Tuffnell et al, and MacKenzie and Cooke have shown is that it is possible safely to achieve delivery within 30 minutes of making the decision-provided that inertia is removed and organisational issues are overcome. Accordingly, we would advise against throwing the baby out with the bath water by dismissing the 30 minute standard as unrealistic or not achievable. We believe that Tuffnell et al and MacKenzie and Cooke may have introduced some confusionclinical negligence schemes for trusts do not require audit to the 30 minute standard, but rather audit to a standard.

Like Tuffnell and MacKenzie, one of us (MG) regularly acts as an expert witness. His experience has been that in 40 cases of litigation about cerebral palsy he has not come across a case where the 30 minute standard was crucial in favour of the claimant. On the contrary, substandard care is most frequently determined by failure to decide that caesarean section is needed. Conversely, cases of cerebral palsy arising from unexpected and catastrophic events (such as major abruption)-where a decision to delivery interval of 20-30 minutes is achieved, but poor outcome cannot be avoided-frequently thwart claimants and provide a defence.

Similar to Tuffnell et al and MacKenzie and Cooke, we found that babies born quickest often have the poorest condition at birth. This is not cause and effect, but rather a reflection of the fact that staff proceed with the greatest haste in the most dire of cases.

Finally, we applaud Tuffnell for his conflict of interest declaration and wonder whether one by MacKenzie was not even more appropriate. Not only does he provide expert reports, but he does so largely on behalf of defendants and is also a counsel member of one of the three medical defence organisations in the United Kingdom.

Malcolm Griffiths consultant obstetrician and gynaecologist

Malcolm.Griffiths@ldh-tr.anglox.nhs.uk

B Sharma specialist registrar

Department of Obstetrics and Gynaecology, Luton and Dunstable Hospital, Luton, Bedfordshire LU4 0DZ

MG regularly provides expert reports for claimants and defendants and is a member of the doctors' support group of the Association for Victims of Medical Accidents.
1 Tuffnell DJ, Wilkinson K, Beresford N. Interval between decision and delivery by caesarean section-are current standards achievable? Observational case series. $B M J$ 2001;322:1330-3. (2 June.)

2 MacKenzie IZ, Cooke I. Prospective 12 month study of 30 minute decision to delivery intervals for "emergency" caesarean section. BMJ 2001;322:1334-5. (2 June.)

\section{Interval between decision and delivery} can be shortened

EDITOR-With reference to the paper by Tuffnell et al on the interval between decision and delivery by caesarean section, ${ }^{1}$ in 1983 we established a protocol that we called "catastrophic caesarean section" for extremely urgent sections in our institution. The procedures are conducted in suboptimal conditions of sterility to reduce extraction time to a strict minimum (no shaving of the patient, no scrubbing of the obstetrician, chlorhexidine disinfectant sprayed on the patient's abdomen, prophylaxis with broad spectrum antibiotics, general anaesthesia unless a locoregional anaesthetic is already in place).

Retrospectively, we analysed the caesarean sections performed between 1995 and 1997 to evaluate their frequency and neonatal and maternal mortality and morbidity. In a series of 818 sections that were performed during that period, 55 sections $(0.8 \%$ of all deliveries) were conducted in extreme urgency (24 for acute fetal distress, 19 for haemorrhage, 9 for prolapsed cord, 2 for breech presentation at complete dilatation, 1 for uterine rupture). We matched every catastrophic caesarean section to the next elective procedure and to the next procedure that was conducted in a semiemergency, which was defined as a caesarean section that was neither elective nor in the catastrophic protocol (most of these were performed for lack of progression of labour or fetal distress). The three groups were comparable in terms of maternal age, gestational age, neonatal weight, and the proportion of primiparous women.

The mean time (from decision to birth) required to perform a catastrophic section was 13 minutes (range 4-27). Although the localisation of the operating theatre is ideal -in the delivery room-and well trained staff is always present, in about $20 \%$ of the catastrophic sections more than 15 minutes were necessary to deliver the baby. The results in term of neonatal mortality and morbidity and maternal morbidity are summarised in the table.

In this small series of patients there was no increase in the frequency of endometritis, urinary tract infections, or wound infections, but the cumulative number of infections tended to be slightly higher in this group. The number of haemorrhages was also higher in this group, but five out of six patients already had a haemorrhage before the start of the section. We believe, therefore, that it is often possible to conduct a catastrophic caesarean section in less than 15 minutes with acceptable maternal morbidity, provided that such a protocol is developed. We advocate its use in all maternity departments.

Alvaro Aguillera consultant

Patricia Barlow head maternity

Serge Rozenberg clinical professor obstetrics and gynaecology

serge.rozenberg@skynet.be

Department of Obstetrics and Gynaecology, Centre Hospitalier Universitaire St Pierre, Free University of Brussels, Brussels 1000, Belgium

1 Tuffnell DJ, Wilkinson K, Beresford N. Interval between decision and delivery by caesarean section-are current decision and delivery by caesarean section-are current 2001:322:1330-3. (2 June.)

Neonatal morbidity and mortality and maternal data by type of caesarean section. Values are numbers unless stated otherwise

\begin{tabular}{lrrrc} 
& Catastrophic $(\mathbf{n = 5 5 )}$ & Semi-urgent $(\mathbf{n = 5 5})$ & Elective $(\mathbf{n}=\mathbf{5 5})$ & P value \\
\hline Neonatal data & & & & \\
\hline Mean neonatal weight $(\mathrm{g})$ & 2983 & 3199 & 3097 & NS \\
\hline Admitted to neonatal intensive care unit & 37 & 21 & 10 & $<0.05$ \\
\hline Mean Apgar score $(1 \mathrm{~min}):$ & & & & \\
\hline All & 5.8 & 7.9 & 8.6 & \\
\hline$>37$ weeks & 6.4 & 8.27 & 8.6 & $<0.05$ \\
\hline$<37$ weeks & 3.7 & 5.75 & 8.3 & \\
\hline$<32$ weeks & 1 & 4.7 & 7 & \\
\hline
\end{tabular}

$$
\text { Apgar score (1 min): }
$$

\begin{tabular}{lllll}
\hline$\leqslant 3$ & 17 & 4 & 1 & $<0.05$ \\
\hline$\leqslant 7$ & 21 & 8 & 2 & $<0.05$
\end{tabular}

\begin{tabular}{lcccc}
\hline Mean Apgar score (5 min): & & & & \\
\hline All & 8.4 & 9.5 & 9.8 & \\
\hline$>37$ weeks & 8.5 & 9.8 & 9.6 & $<0.05$ \\
\hline$<37$ weeks & 6.9 & 8.6 & 10 & \\
\hline$<32$ weeks & 3.75 & 8.3 & 9 & \\
\hline Apgar score at 5 min $\leqslant 7$ & 15 & 2 & 0 & \\
\hline Intubated & 13 & 4 & 0 & $<0.05$ \\
\hline Born dead & 1 & 0 & 0 & \\
\hline Postnatal mortality & 2 & 0 & & \\
\hline Maternal data & & 51 & 6 & \\
\hline Antibioprophylaxis & 54 & 13 & 3 & $<.058$ \\
\hline All infections & 16 & 2 & 3 & $\mathrm{NS}$ \\
\hline Haemorrhage $>1.5$ I & 6 & 5 & &
\end{tabular}




\section{Explanation for absence of adverse} outcomes is needed

EDITOR-The absence of adverse outcomes from delaying urgent deliveries in the papers by Tuffnell et al and MacKenzie and Cooke is anomalous and requires explanation. ${ }^{12}$ The first possible explanation is that the urgent deliveries might not actually have been necessary. This would be consistent with an extensive literature that maintains that current caesarean rates are unnecessarily high. ${ }^{3}$

The second possible explanation concerns the timing metric, the time from decision to caesarean delivery. Patient outcomes depend on the condition of the patient, not on the specific decision time of the obstetrician. Tuffnell et al assume that the time of decision corresponds to a specific and comparable health status among the patients. The absence of an outcome effect arising from 20 minute delays could reflect 20 minute variations in the obstetricians' decision time relative to the patient's condition.

The third possible explanation concerns the measure of adverse infant outcomes. Adverse infant outcomes were measured in terms of medical decisions, the admissions to special care. Perhaps a direct measure of the infant medical status, the Apgar score, would have produced different results.

The fourth possible explanation concerns the impact of nosocomial factors. Tuffnell et al ignored hospital factors and assumed that the decisions both to perform caesarean sections and to admit infants to special care are standardised and consistent at all times throughout the week and throughout the year. Decisions about caesarean sections are complex, and the rates of caesarean section are characterised by hospital variations in practice patterns. ${ }^{45}$

Vincent Richman research associate AlgoPlus Consulting Limited, Halifax, Canada B3J $1 \mathrm{H} 6$

VRichman@hotmail.com

Tuffnell DJ, Wilkinson K, Beresford N. Interval between decision and delivery by caesarean section-are current standards achievable? Observational case series. BMI 2001:322:1330-3. (2 June.)

2 MacKenzie IZ, Cooke I. Prospective 12 month study of 30 MacKenzie IZ, Cooke I. Prospective 12 month study of 30 minute decision to delivery intervals for "emer

3 Flamm BL. Caesarean section: a worldwide epidemic? Flamm BL. Caesarean
Birth 2000;27:139-40.

4 Richman, VV. Lack of local reflection of national changes in caesarean delivery rates: the Canadian experience. $A m J$ Obstet Gynecol 1999; 180:393-5.

5 Richman, VV. Setting goals for reductions in Canadian caesarean rates: Benchmarking medical practice patterns. Am J Obstet Gynecol 1999;181:635-7.

\section{Longer term follow up of surviving babies is required}

EDITOR-James, in his editorial on caesarean section for fetal distress, says that intrapartum hypoxia results in death in about 0.5 in 1000 pregnancies and cerebral palsy in one in 1000 pregnancies. ${ }^{1}$ As the birth prevalence of cerebral palsy is 2.0-2.5/1000, it is implicit that intrapartum hypoxia is the cause of 40-50\% of all cerebral palsy; an estimate that is higher than generally accepted. In the case-control studies from Western Australia and Oxford, only $9 \%$ and 10\% of cases of cerebral palsy of gestational age of 37 weeks were attributable to intrapartum hypoxia. $^{23}$

The main rationale for emergency caesarean section is to prevent hypoxic ischaemic cerebral impairment that becomes clinically manifest as cerebral palsy. In some cases a rapid delivery of the distressed infant will limit the cerebral impairment, but it would be prudent not to be overoptimistic about what emergency caesarean section may achieve. In most cases of cerebral palsy the cerebral impairment occurs prepartum, and the fetal distress exhibited may be the result and not the cause of the impairment. It is a reasonable assumption that a fetus who has had a cerebral insult prepartum is less able to tolerate the stresses of labour than an intact one and, therefore, is more likely to show signs of distress. In such cases, emergency caesarean section may increase rather than decrease the birth prevalence of cerebral palsy by enabling infants impaired prepartum to survive labour.

James notes some of the outcome measures that have been examined in auditing the time taken to caesarean section. These audit measures, such as $\mathrm{pH}$ value of the umbilical artery and Apgar scores, are all made immediately after birth. What is required as part of the audit is a longer term follow up of the surviving infants. This will be time consuming and will require a large sample to show an effect.

\section{P O D Pharoah emeritus professor}

p.o.d.pharoah@liv.ac.uk

M J Platt senior lecturer

Department of Public Health, Unit of Perinatal and Paediatric Epidemiology, University of Liverpool, Liverpool L69 3GB

\footnotetext{
1 James D. Caesarean section for fetal distress. $B M J$ 2001;322:1316-7. (2 June.)

Blair E Stanley F When can cerebral palsy be prevented? The general causal hypotheses by multivariate analysis of a case control study. Paediatr Perinat Epidemiol 1993;7:272301.

3 Gaffiley G, Flavell V, Johnson A, Squier M, Sellers S. Cerebral palsy and neonatal encephalopathy. Arch Dis Child 1994;70:F195-F200.
}

\section{Author's reply}

EDIToR-I am delighted at the response to the study Cooke and I reported on decision to delivery intervals for emergency caesarean sections. Several respondents have illustrated the lack of precision in defining fetal distress and emergency caesarean section.

Banerjee et al reported an increase in caesarean section for fetal distress from $15.4 \%$ to $19.3 \%$ between 1980 and 1999 ; the proportion of caesarean sections for intrapartum fetal distress in Oxford remained constant at approximately 14\% in 1976 and 1996, although this represents an increase from $1.1 \%$ to $2.2 \%$ of all women in labour in the two years quoted.

The definition of "emergency" caesarean section is even more indistinct, as illustrated by the letters from Wee, citing a study reporting a rate of emergency caesarean sections of only $0.7 \%$, and Kinsella et al, of $0.8 \%$. These data most probably refer to "crash" caesarean section, which in our study represented $0.4 \%$ of women delivered; of the 22 when the interval was recorded $17(77 \%)$ were delivered within 30 minutes. This was achieved with a system that had been in place for more than 25 years of obstetric and anaesthetic staff being resident on or near the delivery unit 24 hours of the day, without the need for a public address system.

The conclusion reached by Sharma and Griffiths about maternal safety cannot be drawn either from the report of Tuffnell et al or from our study. Similarly, neither study sought to dismiss the concept of establishing a standard for setting a decision to delivery interval: both have challenged how the decision of 30 minutes had been arrived at Sharma and Griffiths suggest that the fetal condition at birth was a reflection of the severity of the fetal distress that had prompted the caesarean section; they have overlooked the fact that the trend for improving fetal condition, as assessed by cord gas values, occurred with emergency caesarean when fetal distress was not a factor dictating the need for delivery.

Their concerns about expert witness report and clinical research warrants a comment. Expert witnesses provide their views for the benefit of the court and should be unbiased. To suggest that those who conduct clinical research have a potential conflict of interests is a cynical proposition. All of my consultant colleagues in post for more than 12 months prepare reports for medicolegal purposes. This implies that most consultants publishing studies on clinical issues should be admitting a conflict of interest; surely this cannot be correct.

I Z Mackenzie clinical reader in obstetrics and gynaecology

Nuffield Department of Obstetrics and Gynaecology, John Radcliffe Hospital, Oxford OX3 9DU

\section{Authors' reply}

EDITOR-We are pleased that our audit has created so much interest. Some of the correspondents have looked at the indication for delivery and criticised our rate of caesarean section. This assumes that all caesarean sections should only be performed with clear evidence of fetal compromise. This misses the point that in clinical practice we have to deal with risk of fetal compromise and not certainty. If one considers the term breech trial, at least 14 caesarean sections are performed to avoid one case of neonatal morbidity, yet no rational observer would disagree that caesarean section is now the route of choice for the term breech.

When we have audited appropriateness of caesarean section alongside timeliness we have over $95 \%$ peer agreement. As the tests we use in labour to try to identify fetal compromise are neither specific nor sensitive when they identify a case at risk, a decision needs to be made about delivery. When this decision is made then clinicians have always tried to deliver promptly. Standards have been introduced without clear evidence, and our paper considered the issue. Increasing concern about litigation has placed an emphasis on fetal outcome over materna 
safety and the need to provide information to the parents.

Firstly, the lack of adverse outcome reflects, we hope at least in part, the fact that our unit makes decisions at a time before clinically significant fetal compromise occurs. We make no apology for that.

Secondly, it reflects a type two error, as much greater numbers of cases would need to be looked at before any difference was clear. Rates of cerebral palsy attributable to labour are very low and a huge series would be needed to see a difference. The small risk of adverse fetal outcome needs to be considered alongside maternal safety. When either rare outcome occurs criticism of the professionals follows. The debate about this balance needs to take place.

Where does this leave us? Although we should consider ways of speeding up, as have been described, we are more concerned with avoiding prolonged delays and perhaps finding ways of classifying cases more accurately, as also has been suggested. But with increasing litigation and also clinical governance requiring adherence to standards the presence of a national standard is hard to ignore. The concept of individual units creating their own standards may be attractive but is unlikely to be acceptable if there is any major difference from a national standard. It may well be that the sentinel audit of caesarean section can give some national data about what is achieved and could even set targets for what may be reasonable improvements.

D J Tuffnell consultant

K Wilkinson clinical governance support officer

N Beresford senior house officer

Maternity Unit, Bradford Hospitals NHS Trust, Bradford BD9 6R

1 Hannah ME, Hannah WJ, Hewson SA, Hodnett ED, Saigal $S$, et al. Planned Caesarean section versus planned vaginal birth for breech presentation at term: a randomised multicentre trial. Lancet 2000;356:1375-83.

\section{Some words on conflict of interest}

EDITOR-Medical journals-and doctors generally-are in a transition phase in relation to conflicts of interest (or competing interests, as the $B M J$ calls them). We are moving from a phase where it has been normal not to declare them to one where it will be strange not to do so. In this transition phase we are confused about what to declare. My line is "If in doubt, declare," which is why I even declared the death of my pet rabbit in an editorial on animal research. ${ }^{1}$ There are rarely problems when competing interests are declared but often anxieties when they seem to have been hidden.

Expert witnesses are paid-and so do have a financial interest when they are publishing on topics on which they give expert opinions. They should thus declare that they have been expert witnesses. The fact that this applies to many doctors makes it more, not less, important that such competing interests are declared.

Richard Smith editor, BMJ

1 Smith R. Animal research: the need for a middle ground. BMJ 2001;322:248-9.

\section{Take home naloxone for opiate addicts}

Drug misusers may benefit from training in cardiopulmonary resuscitation

EDITOR-Dettmer et al report encouraging initial results of a scheme to give take home naloxone to opiate addicts. ${ }^{1}$ They also refer to training opiate misusers in resuscitation as part of the project. In 1997 we conducted a pilot study of cardiopulmonary resuscitation training in Glasgow, where the incidence of sudden death due to drug misuse is high.

Of the nine volunteers who agreed to participate in the study (all opiate misusers), eight had witnessed a drug overdose. Six described unconsciousness and seven described cyanosis in the victims. The methods used to stimulate the victims ranged from physical stimulation (for example, slapping) $(n=6)$ to injecting intravenous amphetamine $(\mathrm{n}=1)$ or using a spoon to prevent tongue swallowing $(n=1)$. Emergency services had been called in five cases. Only one volunteer reported attempting cardiopulmonary resuscitation.

All volunteers were assessed with a validated scoring system before and after a standard basic life support teaching session. ${ }^{2}$ The group's mean penalty score fell from 94 (range 25-120) to 11 (range $0-20)(\mathrm{P}<0.001$, paired $t$ test for sample means). The two instructors who did the testing and training confirmed that in the test after the instruction all volunteers performed to the standard expected for the Resuscitation Council (UK) advanced life support course.

Most drug misusers in our pilot study had witnessed an overdose, and take home naloxone or cardiopulmonary resuscitation may therefore be useful in Glasgow. We are concerned that not all the misusers called for immediate help, but other studies have suggested that this may be due to fear of the police becoming involved. ${ }^{3}$

Our pilot study showed that this vulnerable group can be trained in basic life support to an acceptable level. If enough drug misusers could be trained in cardiopulmonary resuscitation this might be a useful additional strategy to reduce mortality from opiate overdose.

Colin A Graham specialist registrar in accident and emergency medicine

Victoria Infirmary, Glasgow G42 9TY

ColinGraham@bigfoot.com

Gordon W McNaughton consultant in accident and emergency medicine

Royal Alexandra Hospital, Paisley PA2 9PN

Alastair J Ireland consultant in accident and emergency medicine

Glasgow Royal Infirmary, Glasgow G4 0SF

Kerry Cassells staff nurse

Glasgow Drug Problem Service, Woodside Health Centre, Glasgow G20 7LR

1 Dettmer K, Saunders B, StrangJ. Take home naloxone and the prevention of deaths from opiate overdose: two pilot schemes. BMJ 2001;322:895-6. (14 April.)

2 Graham CA, Lewis NF. A scoring system for the assessment of basic life support ability. Resuscitation 2000;43:111-4

3 Darke S, Ross J, Chen J, Hall W. Overdose among heroin users in Sydney, Australia. II. Response to overdose. Addiction 1996;91:913-7.
Big conclusions are drawn from little evidence

EDITOR-Dettmer et al's paper on two pilot studies to provide take home naloxone to opiate addicts has really answered nothing. ${ }^{1}$ The numbers in the studies were tiny (29 episodes in Berlin, five in Jersey). The response rate was less than $35 \%$, with presumably serious selection bias. The results are anecdotal as far as can be told from the extremely limited methodology presented. The patients were presumed to have done well if a (possibly drug affected) layperson said that they had recovered. What was the length of observation? Was there any follow up? Were there late complications?

The second case presented as anecdotal evidence of benefit raises serious concerns. An agitated layperson runs into a clinic that presumably has trained medical staff on site, gets a naloxone injection made up, runs off, and then returns with the "saved victim." What were the medical staff doing in the meantime? Presumably they were so surprised by this scenario that they thought that leaving a patient to die with airway compromise around the corner was acceptable. This suggests that we are leaving heroin users to deal with "their own" and altering what the response should be - give first aid, provide airway management, call an ambulance, and maybe give naloxone.

With response rates of $35 \%, 60$ other uses of naloxone may not have been reported. Poor outcomes are less likely to be reported by a group that is naturally suspicious of authority, reluctant even to call ambulances, and extremely wary of police involvement

I am deeply concerned that this article was published without any editorial comment. It is seriously flawed research that does not illuminate this difficult area but just increases the shadows. For those who believe that naloxone is a benign drug I would refer them to an article reporting that the use of intravenous naloxone was associated with a $1.3 \%(95 \%$ confidence interval $0.6 \%$ to $4.0 \%)$ rate of adverse events (asystole, fits, pulmonary oedema, and violence). ${ }^{2}$

David Mountain director

Emergency Medicine Department, Sir Charles Gairdner Hospital, Perth 6009, Western Australia, Australia

David.Mountain@health.wa.gov.au

1 Dettmer K, Saunders B, Strang J. Take home naloxone and the prevention of deaths from opiate overdose: two pilot schemes. BMJ 2001;322:895-6. (14 April.)

2 Osterwalder JJ. Naloxone-for intoxications with intravenous heroin and heroin mixtures: harmless or hazardous? A prospective clinical study J Toxicol Clin Toxicol 1996;34:409-16.

\section{Figures in Jersey give no support to} scheme's effectiveness

EDITOR-The study of take home naloxone in Jersey reported by Dettmer et al ran from October 1998 for 16 months, ${ }^{1}$ although the distribution of naloxone to users continued afterwards. The coroner's figures for deaths in Jersey from dependent drug use are dominated by the use of opiates and benzo- 
diazepines. There were no such deaths in 1996, four in 1997, two in 1998, four in 1999 , and three in the first six months of 2000. Such figures give no support to the effectiveness of take home naloxone.

Jersey's results may not be applicable to other settings. It is a small island. Most drug users live fairly near the hospital, and the ambulance staff carry naloxone. It would have been safer if the companions of the person in the anecdotal case had phoned for an ambulance.

Gil Blackwood consultant psychiatrist General Hospital, St Helier, Jersey JE1 3QS castle@itl.net

1 Dettmer K, Saunders B, Strang J. Take home naloxone and the prevention of deaths from opiate overdose: two pilot schemes. BMJ 2001;322:895-6. (14 April.)

\section{Apparent advantages may be balanced by hidden harms}

EDITOR-Providing treatment by proxy for opiate overdose is attractive because it may improve the outcome in overdose victims while developing self esteem in drug using "rescuers." Unfortunately, in the pilot schemes reported by Dettmer et al, where ampoules of naloxone were given to injecting drug users, most of the naloxone seems to have been unaccounted for at the end of the study. ${ }^{1}$ Possibly some of the missing naloxone was used to support "flatlining," in which one drug user stands guard with naloxone while another uses opiates in a dose that far exceeds tolerance; we have come across this practice as a consequence of naloxone being used in emergency ambulances locally.

A further problem with opiate blockers is that they may be used as weapons against other drug users (one of us (AJA) came across this practice after naltrexone was introduced in prison practice). Providing a powerful drug to those who remain involved in the illicit drug market should be done with caution.

Naloxone is not without pharmacological dangers: life threatening side effects may occur in up to $3 \%$ of naloxone treatments for heroin intoxication. ${ }^{2}$ Subjects are unlikely to have reported their involvement in deaths occurring in association with their intervention. Presumably the Jersey data could be examined further: in an island population it may be possible to gather data from other sources such as accident and emergency departments and police to find out what happened to the "missing" naloxone.

Before rushing headlong into the provision of a treatment with unknown risks it is important to discover the extent of harm caused by this intervention so that this can be considered when assessing what are apparent benefits.

A J Ashworth clinical research fellow

A Kidd consultant psychiatrist

Forth Valley Community Drug and Alcoho

Service, Bannockburn Hospital, Bannockburn

FK7 8AH

Dodoc@compuserve.com
1 Dettmer K, Saunders B, Strang J. Take home naloxone and the prevention of deaths from opiate overdose: two pilo schemes. BMJ 200 1;322:895-6. (14 April.)

2 Osterwalder JJ. Naloxone-for intoxications with intravenous heroin and heroin mixtures: harmless or hazardous? A prospective clinical study. J Toxicol Clin Toxicol 1996;34:409-16.

\section{Author's reply}

EDITOR-Our report was intended to stimulate serious consideration of the legitimacy and health benefits of providing homebased supplies of naloxone as part of the comprehensive care of opiate addicts. That consideration is now under way. Our report was a case report (not a research report). Nevertheless, a single life saved is still a life saved. Carefully designed research on this new approach to preventing deaths from overdose is now required to accompany the recommendation of wider availability of naloxone to prevent avoidable deaths from

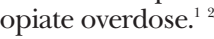

Graham's successful experience of providing training in resuscitation methods in Glasgow is extremely encouraging. Information about naloxone administration should be embedded in broader training about resuscitation and the importance of summoning an ambulance at the earliest opportunity.

We have now encountered further instances of opiate overdose in people who have been saved by peer administration of take home supplies of naloxone provided by the growing number of clinical services that support this additional preventive intervention. This includes selected parts of our own addiction treatment services in south London in which take home naloxone was made available earlier this year (our methadone maintenance clinic and our inpatient detoxification ward were initial sites since these treatments paradoxically increase immediate risk of fatal outcome from overdose).

We strongly support Mountain's proposed sequence of providing airway management, checking breathing, and summoning an ambulance, and only then considering naloxone. Naloxone administration must be an adjunct to, not a replacement for, calling an ambulance. The objective is to cover a critical high risk time and has a similar logic to moving naloxone out of accident and emergency departments into mobile ambulances. We know of cases in which a living victim was dead by the time medical or ambulance staff arrived but who would almost certainly have survived if emergency naloxone had been given during this interim time. These deaths include deaths in institutions (such as prison or drug rehabilitation units). Relevant non-medical staff in these facilities should surely be trained and authorised to administer naloxone while awaiting the arrival of a doctor, as applies to ambulance staff in many countries.

Finally, one further point should be acknowledged. If I were the parent of a heroin addict, I would undoubtedly hold emergency naloxone at home to resuscitate my child more effectively while awaiting an ambulance. I find myself wondering what justification I would offer for withholding this effective interim treatment from my neighbour and his or her child.

John Strang director

National Addiction Centre (Institute of Psychiatry and the Maudsley), London SE5 8AF

A longer version of this letter is published on bmj.com

1 Advisory Council on the Misuse of Drugs (ACMD). Reducing drug-related deaths. London: Home Office, 2000.

2 Strang J, Powis B, Best D, Vingoe L, Griffiths P, Taylor C, et

Strang J, Powis B, Best D, Vingoe L, Grifiths P, Taylor C, et al. Preventing opiate overdose fatalities with take-home naloxone: pre-launch study of possible impact and accep

\section{Bell's phenomenon should not be regarded as pathognomonic sign}

EDITOR-Although Minerva provides welcome light hearted news at the end of the weekly trawl through the $B M J$, I must comment on the picture in the issue of 14 July of the male patient with Bell's phenomenon. ${ }^{1}$

Bell's phenomenon is a normal defence reflex present in about $75 \%$ of the population, resulting in elevation of the globes when blinking or when threatened (try touching your cornea with your finger, for example). It becomes noticeable only when the orbicularis muscle becomes weak as in, for example, bilateral facial palsy associated with the Guillain-Barré syndrome. It is, however, present behind forcibly closed lids in most healthy people and should not be regarded as a pathognomonic sign.

David H Jones specialist registrar ophthalmology Southern General Hospital, Glasgow G51 4TF davana@doctors.org.uk

1 Smith J, Henderson B. (Minerva.) BMJ 2001;323:118. (14 July.)

\section{Doctors should be trained in advanced life support before students are}

Editor-Phillips and Nolan report on the training of medical students in basic and advanced life support. ${ }^{1}$ Of course medical students need training, but what about the rest of us? The authors state that many juniors cannot effectively perform cardiopulmonary resuscitation, and Fielden and Bradbury showed that $83 \%$ of surgeons and anaesthetists (from consultant to senior house officer) failed to give defibrillation according to advanced life support protocols. ${ }^{2}$ Shouldn't it be compulsory for at least one member of the cardiac arrest team to have successfully completed an advanced life support course before we worry about medical students?

Advanced life support courses are oversubscribed, and medically qualified instructors for the courses are in short supply. As resources are scarce surely we should concentrate time and money on training doctors before students. Cardiac arrest teams are usually led by senior house officers in medicine, anaesthesia, or intensive care. 
These are the people who most need training. If this was done, preregistration house officers could learn on the job from those who had undergone standardised resuscitation training. This would make the acquisition of resuscitation skills identical with that of most other clinical skills-that is, with supervised teaching in the clinical setting.

Both students and doctors need training. I agree with the authors in hoping that the new immediate life support course will provide appropriate training for medical students and create more opportunities for doctors to learn much needed resuscitation skills.

Finally, as an advanced life support instructor, I was informed that candidates do not pass or fail, as Phillips and Nolan state, but instead "successfully complete the course," or not, as the case may be. If Nolan, as chair of the advanced life support subcommittee of the Resuscitation Council (UK), can do away with political correctness and use the terms pass and fail then perhaps the rest of us can as well. After all, the end result (whatever the phraseology) is still pass or fail, alive or dead.

Michelle C White specialist registrar in anaesthesia Cheltenham General Hospital, Cheltenham GL53 7AN

mcwdoc@yahoo.com

Phillips PS, Nolan JP. Training in basic and advanced life upport in UK medical schools: questionnaire survey. $B M$ support in UK medical

2 Fielden JM, Bradbury NS. Observational study of defibril-

lation in theatre. BMJ 1999;318:232-3.

\section{Lactulose may help prevent urinary tract infections}

EDITOR-The study by Kontiokari et al did not show a significant reduction in the prevalence of urinary tract infection in women using a lactobacillus drink, but it did show a benefit of cranberry-lingonberry juice. ${ }^{1}$ They concluded that this lack of benefit may have been because they were unable to induce periurethral colonisation with lactobacilli.

Most urinary tract infections are caused by autoinfection, the pathogenic organisms originating from the host's own colonic flora. Previous studies have shown a reduction in the prevalence of urinary tract infections by using lactulose. ${ }^{23}$ This synthetic disaccharide is predominantly used as an osmotic laxative and in managing portosystemic encephalopathy. It is neither absorbed nor metabolised in its transit through the upper gastrointestinal tract, but it is degraded by the bacterial flora of the proximal colon to organic acids. These acidify the proximal colon and result in a dose dependent catharsis.

Lactulose also has several additional properties, including an anti-endotoxin effect and alteration of faecal floral patterns. ${ }^{45}$ This quantitative alteration in faecal floral patterns, with an increase in faecal Lactobacillus acidophilus and a reduction in both coliforms and bacteroides, has been confirmed in our own unpublished work.

We believe that this alteration in faecal floral patterns is responsible for the observed reduction in urinary tract infections. We suggest that a composite effect of the relative increase in lactobacilli associated with the relative reduction in coliforms and other organisms potentially pathogenic to the urinary tract achieves the reduction in urinary tract infections as distinct from pure lactobacillus loading. There may also be a qualitative alteration in bacterial pathogenicity that is relevant to the development of urinary tract infections from using lactulose as an alternative substrate. Manipulation of the faecal floral content using lactulose may prove to be an effective means of preventing urinary tract infections.

M Battle specialist registrar

T Martin preregistration house officer

J Fulton consultant physician

Department of Health Care of the Elderly,

Derriford Hospital, Plymouth PL6 8DH

Competing interests: None declared.

1 Kontiokari T, Sundqvist K, Nuutinen M, Pokka T, Koskel M, Uhari M. Randomised trial of cranberry-lingonberry juice and Lactobacillus GG drink for the prevention of urinary tract infections in women. BMI 2001;322:1571-3. (30 June 2001.)

2 Fulton JD. Infection limitation with lactulose therapy.J Clin Exper Geromtol 1988-9;10:117-24. McCutcheon J, Fulton JD. Lowered prevalence of infection with lactulose therapy in patient

4 Liehr H, Englisch G, Rasenack U. Lactulose-a drug Liehr H, Englisch G, Rasenack U. Lactulose-a drug
with anti-endotoxin effect. Hepato-gastroenterology 1980;27:

Vince A, Zeegen R, Drinkwater J, O'Grady F, Dawson AM. The effect of lactulose on the faecal flora of patients wit hepatic encephalopathy.J Med Microbiol 1974;7:163-8

\section{Audit is powerful tool for accident and emergency service}

EDITOR-Wallis and Guly argue that "an excellent [accident and emergency] service is not achievable when an emergency department is staffed mainly by senior house officers."' As someone whose first job as a senior house officer was in an excellent accident and emergency department, I disagree. An excellent service should be achievable in spite of (medical) staffing consisting mainly of senior house officers.

Much of an accident and emergency department's workload (excepting major trauma) consists of dealing with high volumes of cases of relatively low complexity. Even the emergency management of many serious cases has standard approaches. Such a scenario, whether in medicine or the manufacturing industry, lends itself well to streamlined systems and routine, and to regular quality assurance.

In accident and emergency, that framework should be provided by the leadership (and guidelines) of highly trained senior medical staff and experienced nurses. Inside that framework even inexperienced senior house officers can usefully practise and can safely develop their clinical decision making skills (including by making occasional mistakes). The patient's safety is protected by other systems in place-for example, a radiologist later reviews the ankle $x$ ray film, or a nurse checks the newly sutured wound before dressing it.
To argue that "audit is not an especially useful tool" is wrong, although reviewing the practice of every senior house officer, every six months, in every aspect of accident and emergency care would indeed be pointless. It is precisely in the high volume scenario of accident and emergency medicine that audit can be so powerful-to highlight flaws in the system itself, and to identify systematic changes to prevent their happening in the future. If it is a senior house officer who has the time to perform the audit, and learn a new skill in the process, then so much the better.

The authors' conclusion is that many accident and emergency departments should have more middle (and senior) grade medical staff. I agree. I would argue, however, that to use such precious and skilled resources directly supervising every senior house officer's action would be a waste. Surely it is better to design a watertight ship than to carry extra crew to watch for leaks.

Alastair Ferraro medical senior house officer Queen's Medical Centre, Nottingham NG2 6SF

1 Wallis LA, Guly HR. Improving care in accident and emergency departments. BMJ 2001;323:39-42. (7 July.)

\section{Ethics cost, whether you have them or not}

EDITOR-In a society that is increasingly open, litigious, and multicultural, awareness of the ethical dimensions of everything we do is crucial. As Peile says in his editorial, you don't perceive what you don't perceive. ${ }^{1}$ Most people assume implicitly, and the far right political parties as a credo, that their ethical construct, like their culture, is the a priori norm from which other people's ethics depart to varying degrees, such departures being at best quaint and at worst criminal.

Medical students may be more open minded than the general population, and ethics training, if provided, may be taken on board, but both undergraduate and postgraduate medical training have traditionally been designed to narrow the viewpoint to that of the medical community. With reason; doctors' decision making is frightening enough without introducing an ethical dimension, and professional solidarity, with reference to the medical defence organisations when in extremis, has traditionally been the doctors' barrier against nightmares and litigation. It is crucial that the public shares with the professionals both training in ethics and the pain of applying ethics to difficult decisions.

Clinical governance seems at first sight the natural home for ethical guidance. Their viewpoints are likely to be largely congruent. But it is important that when they are not, the sides are separately represented. The parallel that comes to mind is the separation of the legislature and the judiciary. The National Institute for Clinical Excellence (NICE) suffers from the suspicion that its decisions could be subject to political elbowing. 
Ethics has limped along, funded by goodwill and the hope of rewards in heaven and the merit award lists. To train professionals and the public and to provide the backup that they are going to need will be costly. I have never understood why it should be considered unethical to be properly paid for work on ethics. Until it is generally recognised that ethics is as crucial a determinant of doctors' decision making as the British National Formulary, it will be regarded as an optional extra. It isn't, and we ignore it at our peril.

Judith Harvey general practice non-principal London NW8 9QG

judith.harvey@btclick.com

Peile E. Supporting primary care with ethics advice and education. BMJ 2001;323:3-4. (7 July.)

\section{Stereotyping may highlight diagnoses that might be missed}

EDITOR-One of the important functions of medical practitioners, who frequently have contact with people from other parts of the world, is to be aware of the geographical distribution of diseases so that otherwise treatable conditions are not ignored. In a country such as the United Kingdom where osteomalacia might not be common, it would help rather than hinder to consider "Asian osteomalacia" and then work around it. ${ }^{1}$ The patient in case 2 in Sheikh et al's Lesson of the Week definitely had vitamin $\mathrm{D}$ deficiency; Paget's disease happened to be incidental. No harm was done to this patient by labelling.

Asian osteomalacia is not a single diagnostic entity. The term simply attempts to highlight a clinical possibility that might be overlooked in a less familiar environment. Sanitising terminologies that mean well would have only a detrimental impact.

Romesh Khardori professor-director, endocrinology, metabolism, and molecular medicine Southern Illinois University School of Medicine Springfield, IL 62794-9636, USA

Rkhardori@siumed.edu

1 Sheikh S, Williamson K, Kearley K, Bassindale S, Lancaster T. Lesson of the week: Danger of stereotyping in suspected osteomalacia [commentary by J Kai]. BMJ 2001;323:14951. (21 July.)

\section{Condom gap in Africa is wider than study suggests}

EDITOR-Shelton and Johnston's short report on the unmet need for condoms in sub-Saharan Africa reminds us of how far we are from meeting the urgent demand for the simplest and least expensive method of preventing HIV infection. ${ }^{1}$ Our recent research in South Africa suggests that their calculations are substantial underestimates.

In a cohort study of people procuring public sector condoms from health facilities across South Africa ${ }^{2}$ participants (age range 14-63) reported an average of seven episodes of sexual intercourse a month, or 84 a year. ${ }^{3}$ At this rate, slightly more than one billion condoms would be required to protect each sexual act of the roughly 12 million South African men aged 15-59. If these rates extend across sub-Saharan Africa the unmet need for condoms is probably closer to 13 billion than the 1.9 billion estimated in the paper. In addition, our research suggests that only half of the condoms distributed through the public sector are used in sexual intercourse, potentially doubling the numbers of condoms required for effective prevention of HIV infection.

In South Africa the number of condoms distributed free by the government to the public rose rapidly from 6 million in 1994 to about 198 million in 1999; when these are coupled with commercial brands and condoms sold through social marketing programmes, the total number of condoms distributed approached 210 million. According to Shelton and Johnston's analysis, the distribution of over 200 million condoms should have met the need for condoms in South Africa (17 condoms per man per year $\times 12$ million men $=204$ million condoms required). Yet during 1999, as in previous years, shortages were common at all levels of the distribution chain in the South African Department of Health as the demand for condoms throughout the country greatly outstripped supply.

Shelton and Johnston's underlying point is important, but our findings from South Africa suggest that the condom gap in Africa is much wider than their analysis suggests. The numbers of condoms (and dollars) needed to address the problem may greatly exceed their estimates.

Landon Myer senior scientist

HIV Vaccine and Prevention Unit, South African Medical Research Council, PO Box 198, Mtubatuba 3935, South Africa

landon.myer@mrc.ac.za

Catherine Mathews senior scientist

Health Systems Research Unit, South African

Medical Research Council, PO Box 19070

Tygerberg 7505, South Africa

Francesca Little lecturer

Department of Statistical Sciences, University of

Cape Town, Private Bag, Rondebosch 7701, South Africa

1 Shelton JD, Johnston B. Condom gap in Africa: evidence from donor agencies and key informants. $B M$ 2001;323:139. (21 July.)

2 Myer L, Mathews C, Little F, Karim SS. The fate of free male condoms distributed to the public in South Africa. AIDS 2001;15:789-93.

Myer L, Mathews C, Little F. Condom use and sexua behaviours among individuals procuring free male condoms in South Africa. Sex Transm Dis (in press).

4 South African Department of Health. HIV/AIDS and STD South African Department of Health, HIV/AIDS and STD $1998 \cdot 3: 1-2$

\section{Thrombolysis must be considered after stroke}

EDITOR-Wolfe et al bemoan the lack of progress in bringing acute stroke care in the United Kingdom into the 21st century. ${ }^{1}$ As they point out, evidence shows that focused care of patients with stroke leads to improved outcomes; as in cardiology, a geographically defined unit is the model to aspire to.
The role of thrombolysis in stroke has been marginalised. Thrombolysis is not a panacea for all patients with stroke, just as it has not been in acute coronary syndromes. Nevertheless, grade $1 \mathrm{~b}$ evidence ${ }^{2}$ exists that in selected patients it improves the chance of an excellent functional recovery. ${ }^{3}$ This finding has been largely repeated in a Canadian surveillance study initiated by the government, ${ }^{4}$ which was undertaken to ensure that the benefits of the treatment ("efficacy") could be successfully translated into routine practice ("effectiveness").

Thrombolysis has provided the catalyst for change in the delivery of care. To maximise the number of patients who might benefit from treatment, public awareness of stroke has been heightened. The prehospital and emergency services have been streamlined, access to diagnostic imaging has improved, and multidisciplinary stroke teams have been formed to ensure that safe, effective treatment may be given.

Most patients with stroke-not just those who are eligible for thrombolysis-have access to this focused provision of care, so that more patients have the chance to return to useful lives after a stroke. Furthermore, focused care units provide the therapeutic environment in which the broader population of patients with stroke may be studied and entered into randomised controlled trials. While receiving optimal medical care they help us in our endeavour to fill in the evidence gap.

Advancing the delivery of better care for the majority of patients with stroke has been a major spin off from the provision of appropriate care to the minority. Change in behaviour and attitudes require a lever, and thrombolysis in acute ischaemic stroke has had beneficial effects far beyond those of the treatment itself.

James Kennedy Canadian Stroke Network stroke fellow

James.Kennedy@CalgaryHealthRegion.ca

Alastair M Buchan professor of stroke neurology University of Calgary, Foothills Medical Centre, Calgary, Alberta, Canada T2P 0G7

Henry J M Barnett emeritus professor John P Robarts Research Institute, PO Box 5015, 100 Perth Drive, London, Ontario, Canada N6A $5 \mathrm{~K} 8$

1 Wolfe C, Rudd A, Dennis M, Warlow C, Langhorne P. Taking acute stroke care seriously. $B M J$ 2001;323:5-6. (7 July) 2 Oxford Centre for Evidence Based Medicine. Levels of evidence. May 2001. http://cebm.jr2.ox.ac.uk/docs levels.html (accessed $4 \mathrm{Oct}$ ).

3 National Institute of Neurological Disorders and Stroke rtPA Stroke Study Group. Tissue plasminogen activator for acute ischemic stroke. N Engl J Med 1995;333:1581-7.

4 Hill MD, Buchan AM for the CASES Investigators. The Canadian Activase for stroke effectiveness study (CASES): interim results. Stroke 2001;32:323 (abstract).

5 Buchan AM, Barber PA, Newcommon N, Karbalai HG, Demchuk AM, Hoyte KM, et al. Effectiveness of t-PA in acute ischemic stroke: outcome relates to appropriateness. Neurology 2000;54:679-84.

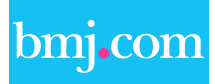

\section{Rapid responses}

Correspondence submitted electronically

is available on our website 